\title{
BIOPARTICULATE SOLUBILIZATION AND BIODEGRADATION IN SEMI-CONTINUOUS AEROBIC THERMOPHILIC DIGESTION
}

\author{
C. A. MASON, G. HAMER*, TH. FLEISCHMANN, and C. LANG \\ Institute of Aquatic Sciences, Swiss Federal Institute of Technology Zürich, and Swiss Federal Institute for \\ Water Resources and Water Pollution Control, Ueberlandstrasse 133, CH-8600 Dübendorf, Switzerland
}

(Received September 12, 1986; revised February, 1987)

\begin{abstract}
The effects of charge size, cycle time, and the presence of added $\mathrm{N}$ on the extent of solubilization and biodegradation of microbial solids were investigated during semi-continuous operation of an aerobic thermophilic digestion process. Use of a charge size of $50 \%$ of the bioreactor operating volume resulted in the removal of more than $59 \%$ of the total suspended solids concentration in the feed and showed enhanced performance compared with when a $25 \%$ charge size was used. The addition of a supplementary $\mathrm{N}$ source resulted in enhanced dissolved organic carbon (DOC) concentrations with the $50 \%$ charge size, but did not affect overall solids removal. With the $25 \%$ charge size, addition of a supplementary $\mathrm{N}$ source resulted in an overall improvement in process performance.
\end{abstract}

\section{Introduction}

Both microbial growth theory and most research results concerning microbial biodegradation processes are only directly relevant to soluble and/or miscible $\mathrm{C}$ energy substrates. This is in spite of the fact that particulate biodegradable substrates are widely encountered in wastewaters and waste sludges and in natural aquatic environments. Waste sludge biodegradation processes require solubilization of the particulate matter present prior to biodegradation of the released soluble lysis products. Despite the fact that the rate of solubilization is the limiting step in waste sludge biotreatment, relatively little research has been directed towards this aspect of such processes.

Recently, several West European governments have shown concern about the effectiveness of existing waste sludge treatment technologies, particularly with regard to the removal of pathogenic organisms and toxic chemicals. Sludge treatment under aerobic thermophilic conditions has been proposed as a means of improving current sludge treatment technology. It is intended that such processes be operated as pretreatment processes in conjunction with installed conventional anaerobic mesophilic sludge treatment. Aerobic operation in the first stage is preferable when toxic compounds which are essentially recalcitrant under anaerobic conditions but which can be biodegraded under aerobic are present in waste sludges (McEvoy and Giger, 1986).

Several municipal aerobic thermophilic waste sludge treatment plants operate in the semi-continuous mode (Zwiefelhofer, 1985; Wolinski, 1985) as opposed to continuous flow mode described by most researchers (Smith et al., 1975; Keller and Berninger, 1984; Kabrick and Jewell, 1982). The former have the advantage of a defined minimum

* Author for all correspondence. 
retention time, a factor of critical importance with respect to the hygienization potential of the process.

Our understanding of the solubilization/biodegradation of microbial solids in aerobic thermophilic biotreatment systems remains scant. Hamer and Mason (1987) have proposed a model for the biodegradation of microbial solids in a semi-continuous system whereby growth of the aerobic thermophilic population occurs on the released soluble compounds contained in the cell cytoplasm following enzymatic degradation of a part of the feed microbe cell wall. The cytoplasm is under a high osmotic pressure such that lysis of the feed microbe cell wall easily causes release of the cell contents. Growth on this soluble substrate occurs simultaneously with the production of acetate when the system is run under $\mathrm{O}$ restricted conditions. As time progresses, the remainder of the cell wall fractions is hydrolyzed into utilisable soluble substrates whilst the accumulated acetate is used as an additional growth substrate. The effects of varying the charge size and cycle time (minimum particle residence time) on the performance of this process cycle have never been investigated in detail. Moreover, most treatment plants operate only on weekdays whereby on Mondays to Fridays a $24 \mathrm{hr}$ cycle is normal, whereas charging the reactor between Friday and Monday allows a 3 day cycle time. Therefore, it was also of interest to examine the effects of cycle time on process performance.

The final variable investigated in these experiments was the question as to whether there was a requirement for addition of further nutrients. Whilst phosphate is most unlikely to be limiting in such processes, the availability of $\mathbf{N}$ could well be a problem. Nitrogen, when not present in excess would have to be obtained from organic-N components of the feed microbial cells. The differences in behavior of process systems in the presence of excess inorganic- $\mathrm{N}$ and under reduced availability of such sources were assessed.

\section{Materials and Methods}

\subsection{BIOREACTOR AND OPERATING CONDITIONS}

A 1.5 L bioreactor (Bioengineering $\mathrm{AG}, \mathrm{Wald}, \mathrm{CH}$ ) with full measurement instrumentation, i.e., $\mathrm{pH}$, dissolved $\mathrm{O}$ concentration, temperature and impellar speed monitoring, was used for the experiments. Air $\left(6 \mathrm{~L} \mathrm{hr}^{-1}\right)$ was sparged into the bioreactor which was operated with an impellar speed of $900 \mathrm{rpm}$. The operating temperature was maintained constant at $60^{\circ} \mathrm{C}$ and the working volume was $1300 \mathrm{~mL}$. The $\mathrm{pH}$ was not controlled.

\subsection{AEROBIC THERMOPHILIC CULTURE AND FEED}

Aerobic thermophilic microbes were obtained from an operating municipal waste sludge aerobic thermophilic digestor (UTB, Umwelttechnik Buchs AG, Buchs/SG, CH). Pressed bakers yeast (at concentrations between 30 and $60 \mathrm{~g} \mathrm{~L}^{-1}$ ) as the sole biodegradable $\mathrm{C}$ and $\mathrm{N}$ source was suspended in a nutrient solution containing $\mathrm{KH}_{2} \mathrm{PO}_{4}$, $8 \mathrm{~g} \mathrm{~L}^{-1} ; \mathrm{K}_{2} \mathrm{HPO}_{4}, 5.7 \mathrm{~g} \mathrm{~L}^{-1} ; \mathrm{ZnO}, 3.26 \mathrm{mg} \mathrm{L}^{-1} ; \mathrm{FeCl}_{3} 6 \mathrm{H}_{2} \mathrm{O}, 43.2 \mathrm{mg} \mathrm{L}^{-1}$; $\mathrm{MnCl}_{2} 4 \mathrm{H}_{2} \mathrm{O}, 16 \mathrm{mg} \mathrm{L}^{-1} ; \mathrm{CuCl}_{2} 2 \mathrm{H}_{2} \mathrm{O}, 1.36 \mathrm{mg} \mathrm{L}^{-1} ; \mathrm{CoCl}_{2} 6 \mathrm{H}_{2} \mathrm{O}, 3.8 \mathrm{mg} \mathrm{L}^{-1}$; 
$\mathrm{H}_{3} \mathrm{BO}_{4}, 0.5 \mathrm{mg} \mathrm{L}^{-1}$; and $\mathrm{MgCl}_{2}, 0.2 \mathrm{~g} \mathrm{~L}^{-1}$. The stock solution was stored at $4{ }^{\circ} \mathrm{C}$ for no longer than 5 days. Start-up was carried out by inoculating $500 \mathrm{~mL}$ aerobic thermophilic sludge into $800 \mathrm{~mL}$ of preheated $\left(60^{\circ} \mathrm{C}\right)$ yeast suspension. The bioreactor was operated on a fill and draw cycle of either 25 or $50 \%$ bioreactor volume withdrawal of spent broth, followed by addition of the same volume of fresh yeast cell suspension. Yeast addition was carried out slowly so as not to cause a drop in temperature.

\subsection{ANALYTICAL}

$5 \mathrm{~mL}$ samples were centrifuged at $30000 \times \mathrm{g}$ and the supernatant removed. The solids were resuspended in water, poured into tared crucibles and left overnight at $105^{\circ} \mathrm{C}$. They were reweighed after cooling in a dessicator.

After drying overnight, the crucibles used to determine dry weight were placed in an oven at $600{ }^{\circ} \mathrm{C}$ for at least $5 \mathrm{hr}$, allowed to cool and then reweighed.

Appropriate dilutions of the supernatant were made and the DOC assayed directly on a TOCOR total organic $C$ analyzer (Maihak $A G$, Hamburg, D). Inorganic $C$ was removed by acidification and sparging with $\mathrm{N}$.

$\mathrm{NH}_{4}^{+}-\mathrm{N}$ was measured in the extracellular medium using an automated $\mathrm{N}$ analyzer (Skalar Analytical, Breda, NL).

All chemicals were of analytical grade and supplied by either Fluka (Buchs/SG, CH) or Merck (Darmstadt, D).

\section{Results}

The extent of solubilization and biodegradation of microbial cells in semi-continuous culture in which aerobic thermophilic bacteria are growing was investigated to examine the effects of charge size, bioreactor residence time and inorganic- $N$ availability. Differences were obtained with respect to the amount of solids biodegraded at different residence times and inorganic- $N$ source concentrations in the bioreactor feed. The results are shown in Figures 1 to 5. Figure 1 shows the amounts of total suspended solids in the feed and after 7 and $24 \mathrm{hr}$ in the bioreactor. From the data for a $25 \%$ fill and draw volume and 1 day cycle time it can be seen that the amount of solubilization and biodegradation occurring between 7 and $24 \mathrm{hr}$ is almost negligible, i.e., most effects occur during the first $7 \mathrm{hr}$ in the bioreactor. Some increase in the amount of solids degraded between 24 and $72 \mathrm{hr}$ can be seen from the data from 3 day cycle times. Significantly better biodegradation in terms of the percentage of total solids removed can be achieved with the larger fill and draw volume $(50 \%)$, where the extent of total solids removal was consistently greater than $59 \%$ (of feed microbial cell concentration) irrespective of cycle time and the presence or absence of an inorganic- $\mathrm{N}$ in the feed (Figure 2). When a $25 \%$ charge size was used, the degradation efficiencies were lower and affected by the presence or absence of $\mathrm{N}$ in the feed. The volatile suspended solids were found to behave in the same manner as the total suspended solids with respect to the effects of charge size and $\mathrm{N}$, but showed higher removal efficiences at longer cycle times for the larger charge size (Figure 3). For both volatile and total suspended solids 

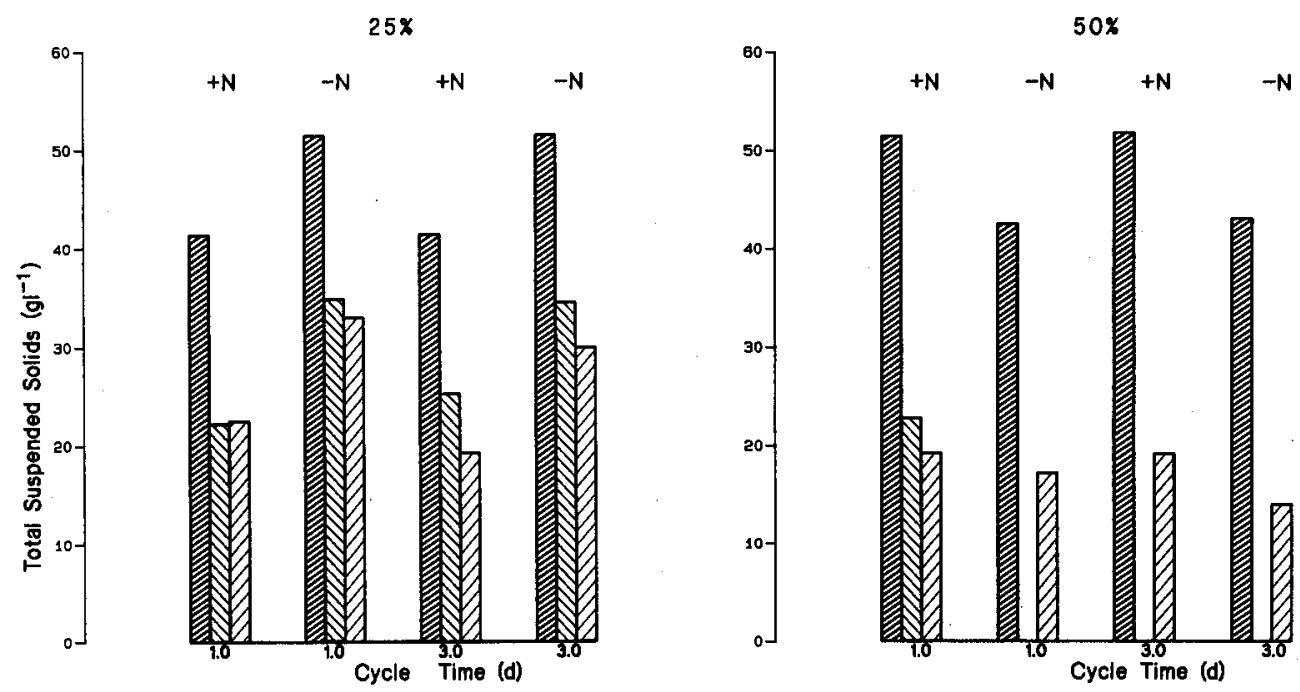

Fig. 1. Total suspended solids in the feed (first bar), after $7 \mathrm{hr}$ (middle bar) and after $24 / 72 \mathrm{hr}$ as a function of cycle time, the presence $(+N)$ or absence $(-N)$ of inorganic- $N$ in the feed and charge size $(25$ and $50 \%$ of bioreactor operating volume).
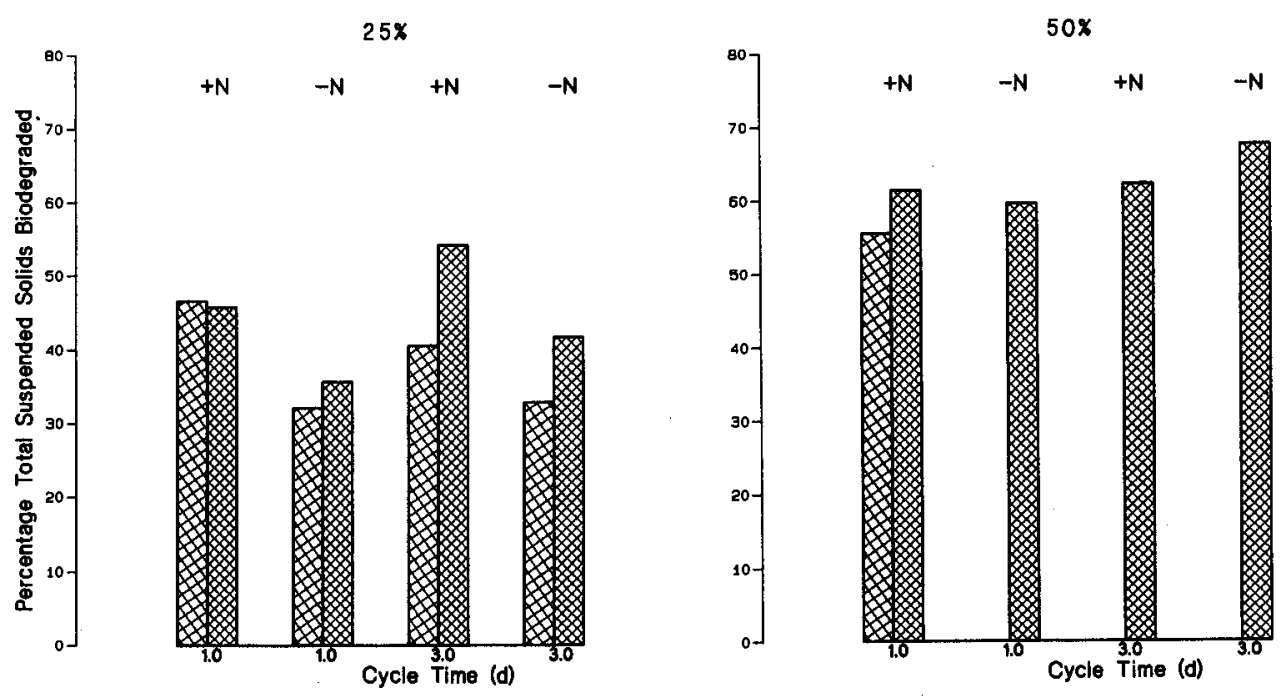

Fig. 2. The amount of total suspended solids biodegraded as a percentage of the concentration in the feed after $7 \mathrm{hr}$ (left hand bar, where data available) and after $24 / 72 \mathrm{hr}$ as a function of cycle time, the presence $(+\mathrm{N})$ or absence $(-\mathrm{N})$ of inorganic-N in the feed and charge size (25 and $50 \%$ of biorecator operating volume).

a significant increase in the amount biodegraded could be measured after $72 \mathrm{hr}$ compared to the amount biodegraded after $7 \mathrm{hr}$ where data are available.

The results obtained from DOC analysis are shown in Figure 4 . The data for a $25 \%$ charge size show some consistency while that for $50 \%$ charge size shows very different 

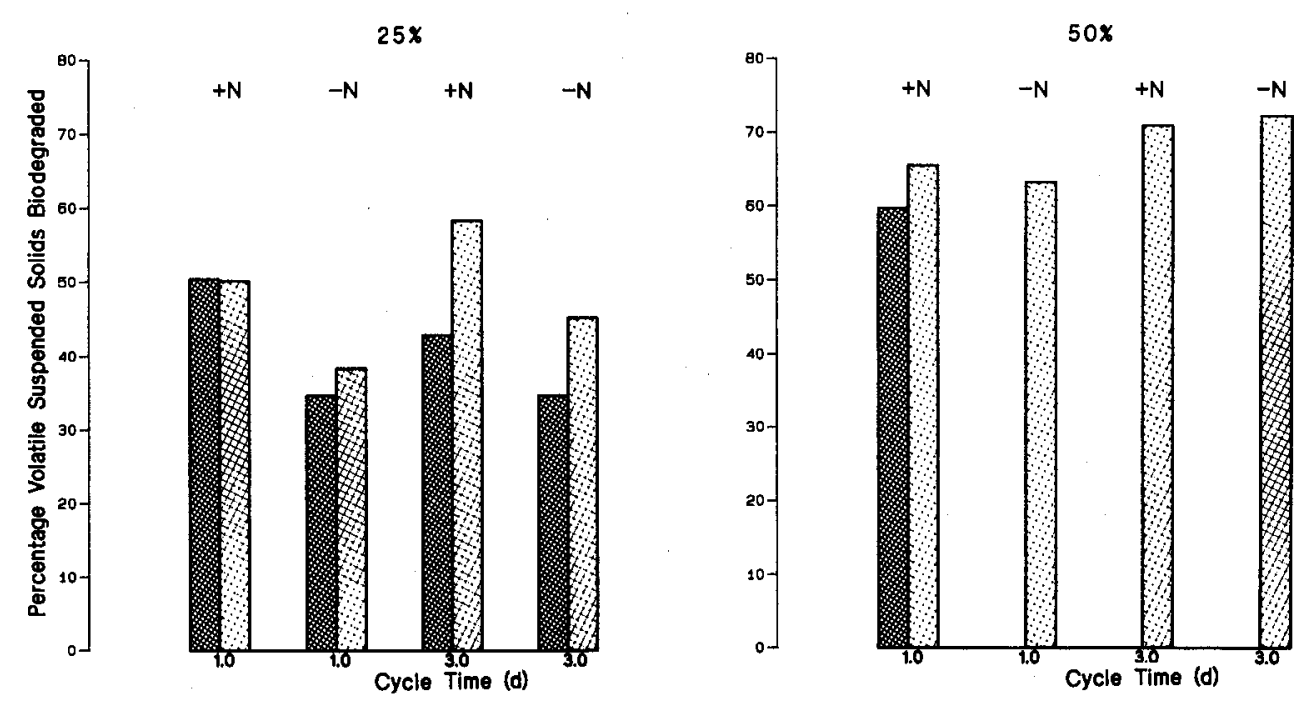

Fig. 3. The amount of volatile suspended solids biodegraded as a percentage of the concentration in the feed after $7 \mathrm{hr}$ (left hand bar, where data available) and after $24 / 72 \mathrm{hr}$ as a function of cycle time, the presence $(+\mathrm{N})$ or absence $(-\mathrm{N})$ of inorganic-N in the feed and charge size $(25$ and $50 \%$ of bioreactor operating volume).
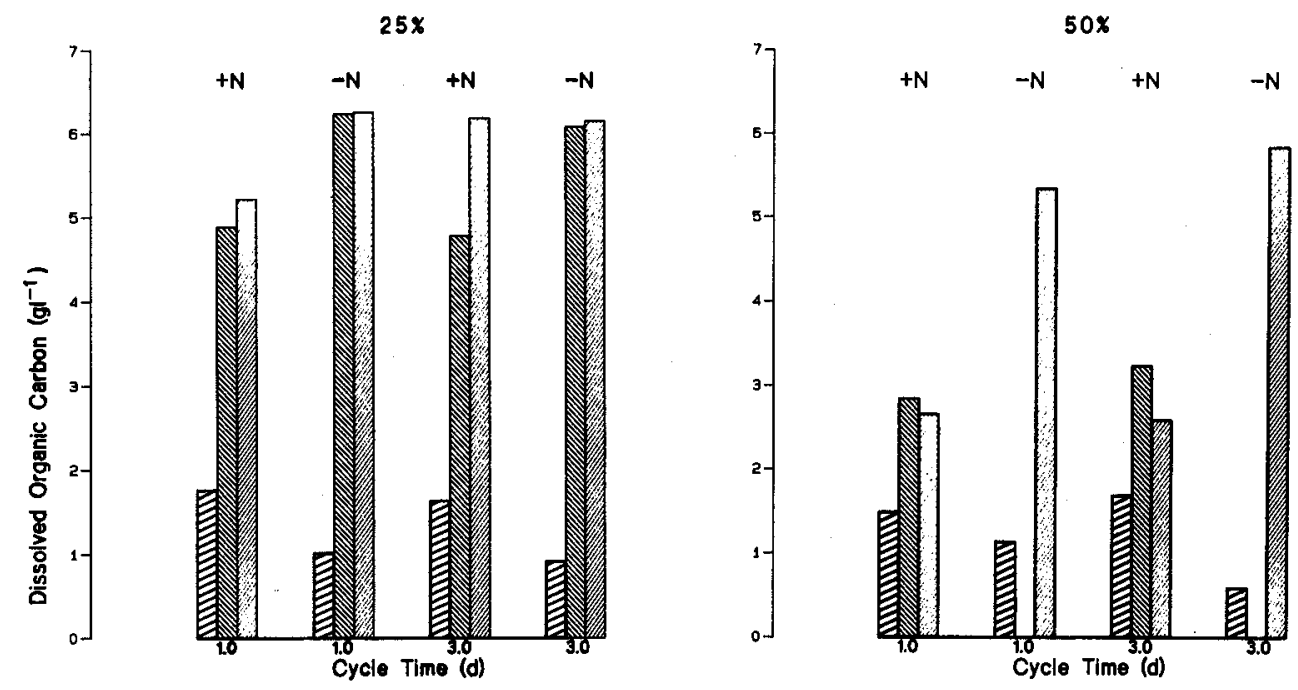

Fig. 4. Dissolved organic carbon concentration in the feed (first bar), after $7 \mathrm{hr}$ (middle bar) and after $24 / 74 \mathrm{hr}$ as a function of cycle time, the presence $(+N)$ or absence $(-N)$ of inorganic-N in the feed and charge size ( 25 and $50 \%$ of bioreactor operating volume).

results in the presence of and in the absence of added inorganic-N. Under conditions of $\mathrm{N}$ excess with a $50 \%$ bioreactor volume charge size, the DOC concentration at the end of the charge period ( 24 or $72 \mathrm{hr}$ ) is only slightly higher than the influent DOC, and there is some suggestion as to an actual reduction in DOC during the biodegradation 
process. Very much higher concentrations of DOC could be found in the bioreactor at both 1 day and 3 day cycle times in the absence of added $\mathrm{N}$. When $25 \%$ bioreactor volume charge size was used, the DOC remained constant between 7 and 24/72 hr in the absence of added $\mathrm{N}$ whilst slight increases in the levels of DOC were found when $\mathrm{N}$ was added to the feed.

The data for inorganic-N (Figure 5) indicate that for the smaller charge size, inorganic- $\mathrm{N}$ accumulates in the absence of an added inorganic- $\mathrm{N}$ source, such that the
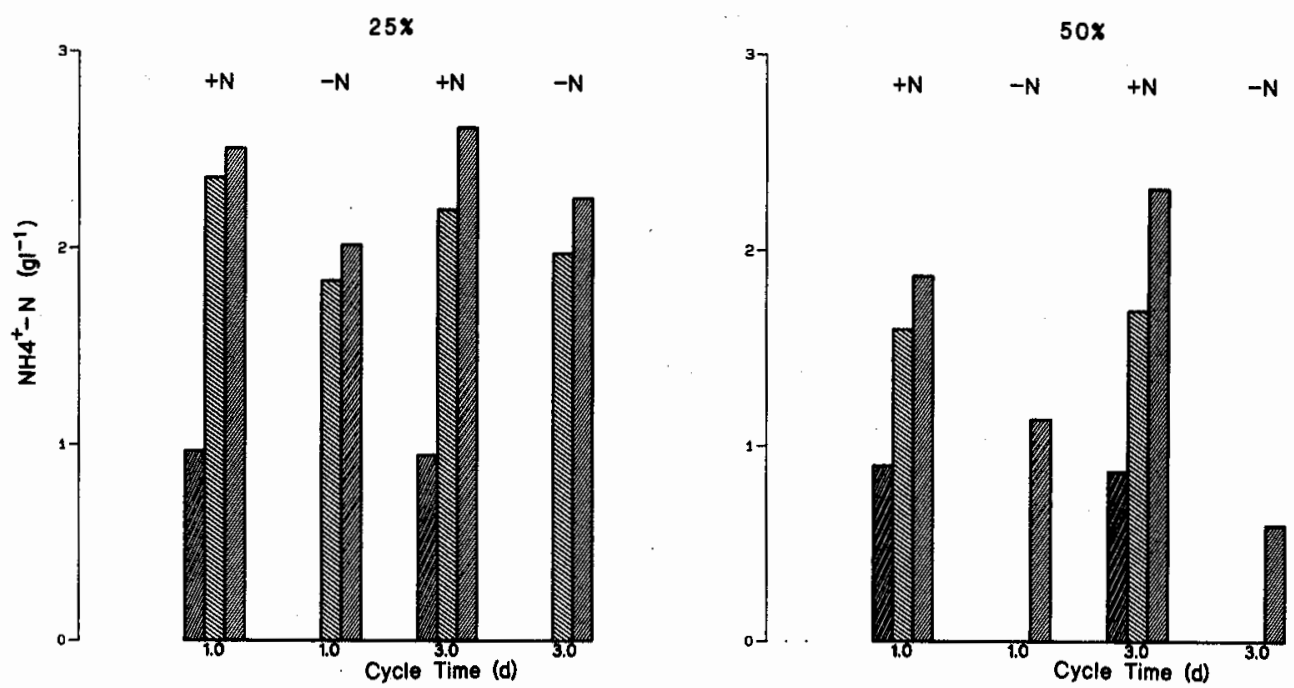

Fig. 5. $\mathrm{NH}_{4}^{+}-\mathrm{N}$ in the feed (first bar), after $7 \mathrm{hr}$ (middle bar) and after $24 / 72 \mathrm{hr}$ as a function of cycle time, the presence $(+N)$ or absence $(-N)$ of inorganic-N in the feed and charge size $(25$ and $50 \%$ of bioreactor operating volume).

concentrations of $\mathrm{NH}_{4}^{+}-\mathrm{N}$ found at the end of the $24 \mathrm{hr}$ period are nearly as high as those found when $\mathrm{NH}_{4}^{+}-\mathrm{N}$ is included in the feed. Use of the $50 \%$ bioreactor volume charge size resulted in a much lower accumulation of $\mathrm{NH}_{4}^{+}-\mathrm{N}$ in the bioreactor when $\mathrm{N}$ was omitted from the feed compared with when $\mathrm{N}$ was present. It should be noted that some loss of $\mathrm{NH}_{4}^{+}-\mathrm{N}$ was undoubtedly occurring by stripping from the bioreactor due to non-optimal outlet gas condenser operation and thus resulted in an odor of ammonia around the bioreactor.

The $\mathrm{pH}$ in the bioreactor was not controlled and the variation in $\mathrm{pH}$ under different sets of conditions can be seen in Figures 6 and 7. The initial values are not important since they will depend on the circumstances prevailing during the time preceding the start of operation. The $\mathrm{pH}$ values for a charge size of $50 \%$ of the bioreactor volume (Figure 7) clearly show that the greatest degree of variation occurs with a 1 day cycle time both with and without added $\mathrm{N}$. The effect of fresh feed addition on the $\mathrm{pH}$ can be clearly seen in this figure.

In the presence of $\mathrm{N}$, operation during the weekend ( 3 days) allows a significant rise in the $\mathrm{pH}$ value, whilst in the absence of $\mathrm{N}$ the value at the end of the experiment is little different from that at the start. 


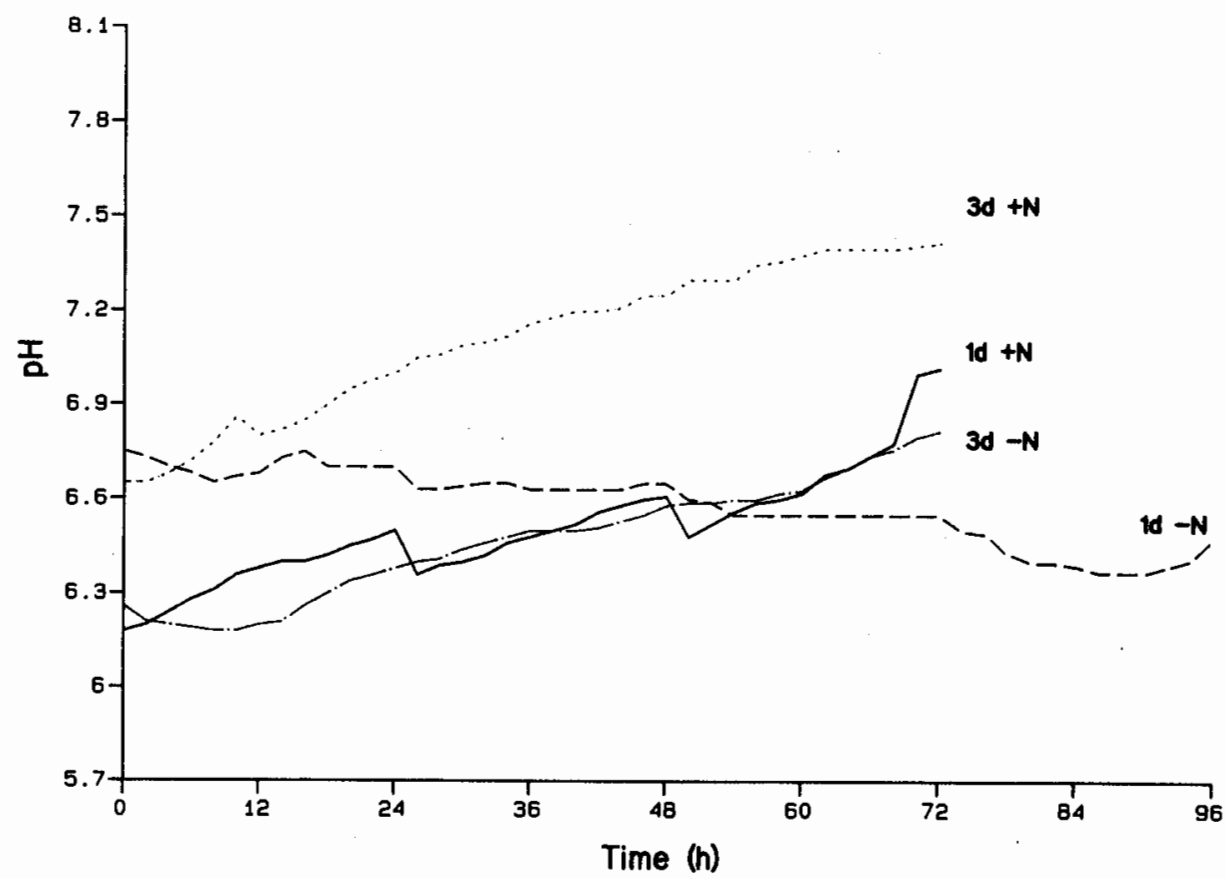

Fig. 6. Variation in pH as a function of the cycle time and of the presence $(+N)$ or absence $(-N)$ of inorganic-N in the feed for a charge size of $25 \%$ of the bioreactor operating volume.

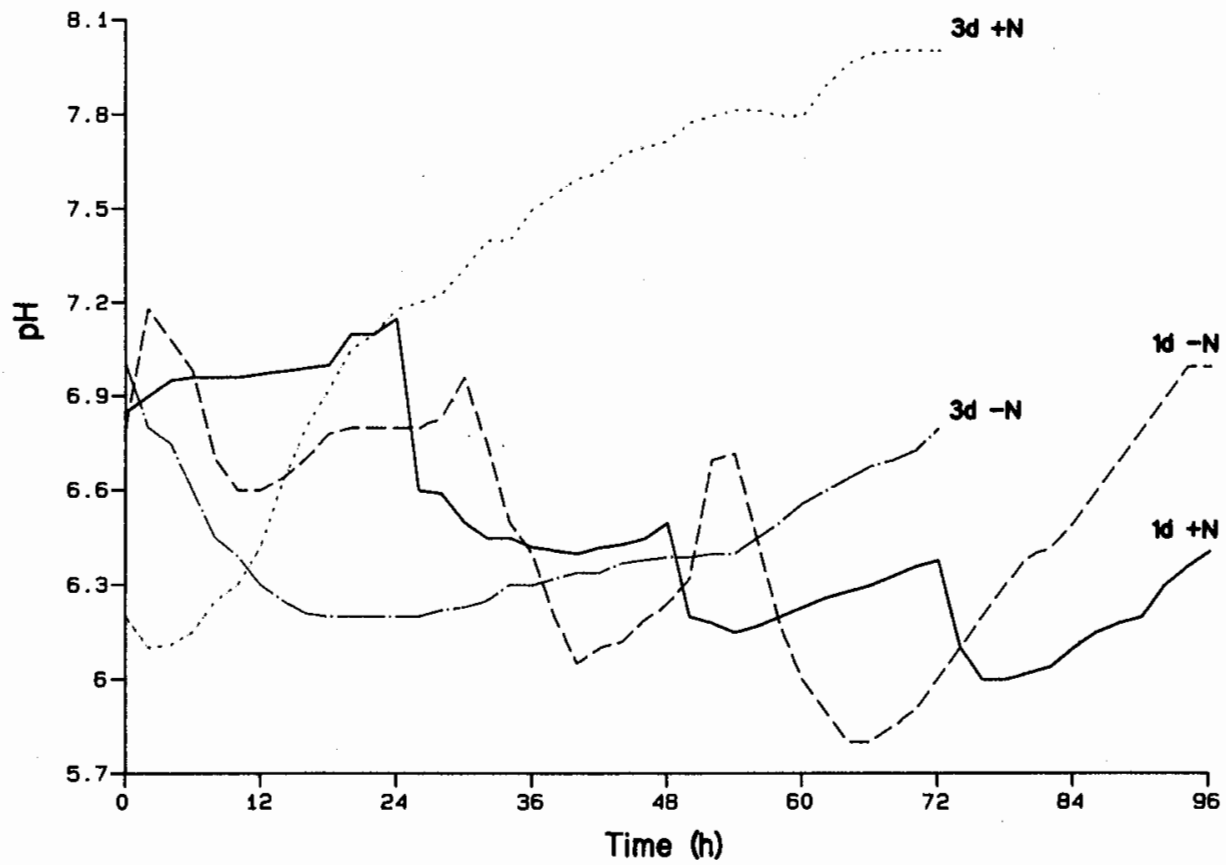

Fig. 7. Variation in pH as a function of the cycle time and of the presence $(+N)$ or absence $(-\mathbf{N})$ of inorganic- $\mathbf{N}$ in the feed using a charge size of $50 \%$ of the bioreactor operating volume. 
With a charge size of $25 \%$ of the bioreactor volume (Figure 6), less effects on $\mathrm{pH}$ can be seen and a gradual rise in $\mathrm{pH}$ occurred in all cases, with the exception of 1 day cycle times in the absence of $\mathrm{N}$ where the $\mathrm{pH}$ ended each $24 \mathrm{hr}$ only slightly lower than at the start of the cycle.

\section{Discussion}

One of the key factors controlling the rate of microbial growth is the availability of nutrients. When a pool of soluble nutrients is available, both metabolism and growth can occur optimally provided that no nutrient is present at either growth limiting or inhibitory concentrations. When microbes are presented with organic- $\mathrm{N}$, this must first be converted into a readily assimilable form. The thermophilic process microbes in the system described here are faced with such a problem. Clearly, when $\mathrm{N}$ is provided as ammonia, the need to release $\mathrm{N}$ from proteins, RNA and DNA, and from feed microbe cell wall organic polymers is not growth restricting. However, when excess soluble inorganic- $\mathrm{N}$ is unavailable, the growth and metabolic efficiency of the thermophilic process microbes is reduced. Egli and Quayle (1986) showed that for N-sufficient growth of a methylotrophic yeast, a $\mathrm{C}$ to $\mathrm{N}$ ratio of $12: 1$ was necessary. For the bacterium Klebsiella pneumoniae, Egli and Fiechter (1981) showed that this ratio was $8.75: 1$. If it is assumed that the empirical formula for microbial biomass on an ash and moisture free basis is: $\mathrm{CH}_{1.8} \mathrm{O}_{0.43} \mathrm{~N}_{0.23}$ (Hamer and Harrison, 1979) and a typical C content for microbial biomass to be $47 \%$ then this corresponds to a $\mathrm{N}$ content in biomass of $12.6 \%$. Thus the theoretical $\mathrm{C}$ to $\mathrm{N}$ ratio in microbial biomass is $4.35: 1$, a ratio which suggests sufficient $\mathrm{N}$ availability when microbial cells are used as a substrate for growth of thermophilic process microbes assuming the $\mathrm{N}$ requirement of such microbes is not excessively high. From the results presented here it is apparent that in the aerobic thermophilic digestion process, one of the major rate limiting steps could be the release of $\mathrm{N}$ from complex polymeric particles. Eastman and Ferguson (1981) discussed the fact that hydrolysis of particulate material constituted the rate limiting step in anaerobic digestion processes. In aerobic thermophilic digestion processes where soluble $\mathrm{N}$ resources are limited, the further hydrolysis of $\mathrm{N}$ bound in organic polymers may further limit the overall rate of digestion.

The system investigated here was a semi-continuous process such that the effect of reduced $\mathrm{N}$ availability in the feed was alleviated by accumulation which took place as a result of only limited removal of the bioreactor contents at the end of each cycle time. The effect of removing a large proportion of the bioreactor contents $(50 \%$ as opposed to $25 \%$ of the bioreactor volume) on $\mathrm{N}$ accumulation can also be clearly seen (Figure 5 ).

The advantages of operating with larger charge sizes can be related to the amount of readily utilizable $\mathrm{C}$ and energy substrates in the system. Given that lytic products from lysis of the feed microbial cells will be readily utilized, the remaining cell wall debris is likely to be effectively only slowly biodegradable. Since, with a $50 \%$ bioreactor volume charge size more of the readily utilizable soluble lytic product will be present a higher degree of biodegradation is possible. In addition, use of the larger charge size prevents high level accumulation of slowly biodegradable material. 
The variations in $\mathrm{pH}$ also demonstrate advantages for the process as a result of a five day (Monday to Friday) operation. During the one day cycle time a progressive decrease in $\mathrm{pH}$ occurs, it is only due to the fact that 3-day (weekend) cycle time allows a regeneration of the $\mathrm{pH}$ to higher values that a collapse of effective operation as a result of low $\mathrm{pH}$ conditions, causing inhibition, is prevented.

Hamer and Mason (1987) presented a model for semi-continuous operation of the aerobic thermophilic process. This clearly showed that variation in thermophilic process microbe activity and thus in the rates of substrate utilization could be measured as a function of time. The system investigated had a repeated three day cycle time. In systems with a 1 day cycle time, these variations in process microbe activity are unlikely to have any significance since the bacterial activity should remain consistently high due to repeated substrate addition. When the one day cycling is interrupted by a 3 day cycle (Friday-Monday) the effects of process thermophilic microbe inactivation may reduce process efficiency.

\section{Conclusions}

Semi-continuous operation of the aerobic thermophilic process for the biodegradation of microbial solids results in high substrate removal. Addition of inorganic-N results in enhanced removal of solids especially under conditions where low charge sizes are used. Operation with $50 \%$ bioreactor volume charge size results in slightly enhanced performance over $25 \%$ bioreactor volume charge size. The effects of 3 day cycle time (weekends) are effectively only seen in $\mathrm{pH}$ effects and offer only advantages in this respect for overall process efficiency.

\section{Acknowledgments}

C. A. Mason and C. Lang were supported by the Swiss National Programme 7D. We are also grateful to the Swiss Federal Institute for Water Resources and Water Pollution Control (EAWAG) for additional financial support.

\section{References}

Eastman, J. A. and Ferguson, J. F.: 1981, J. Wat. Poll. Cont. Fed. 53, 352.

Egli, Th. and Fiechter, A.: 1981, J. Gen. Microbiol. 123, 365.

Egli, Th. and Quayle, J. R.: 1986, J. Gen. Microbiol. 132, 1779.

Hamer, G. and Harrison, D. E. F.: 1979, Proc. Inst. Petroleum Symp. Canterbury, G.B., p. 59.

Hamer, G. and Mason, C. A.: 1987, Bioprocess Engng., in press.

Kabrick, R. M. and Jewell, W. J.: 1982, Water Res. 16, 1051.

Keller, U, and Berninger, I.: 1984, Gas-Wasser-Abwasser 64, 215.

McEvoy, J. and Giger, W.: 1986, Environ. Sci. Technol. 20, 376.

Smith, J. E. Jr., Young, K. W. and Dean, R. B.: 1975, Water Res. 9, 17.

Wolinski, W. K.: 1985, Wat. Poll. Cont. 84, 433.

Zwiefelhofer, H. P.: 1985, Conserv. Recyc. 8, 285. 